\title{
High-dose Cytarabine/Rituximab Regimen
}

National Cancer Institute

\section{Source}

National Cancer Institute. High-dose Cytarabine/Rituximab Regimen. NCI Thesaurus.

Code C160538.

A regimen consisting of high-dose cytarabine and rituximab that may be used in the treatment of Burkitt Lymphoma. 